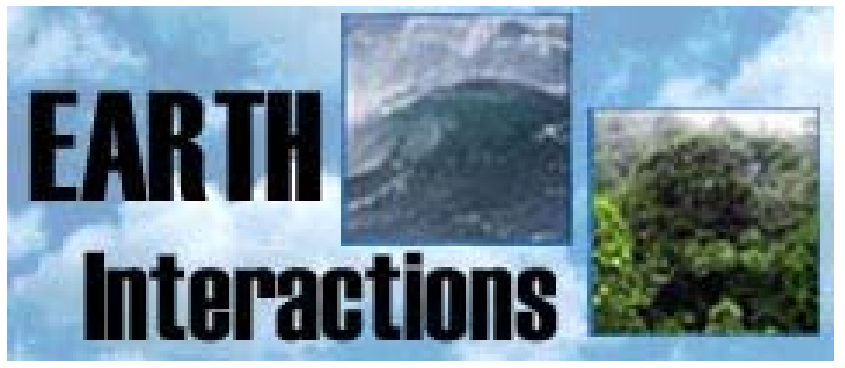

Copyright (C) 2004, Paper 8-011; 8,620 words, 7 Figures, 0 Animations, 2 Tables. http://EarthInteractions.org

\title{
Ecodynamic and Eddy-Admitting Dimethyl Sulfide Simulations in a Global Ocean Biogeochemistry/ Circulation Model
}

\section{Shaoping Chu, Scott Elliott,* and Mathew Maltrud}

The Climate Ocean Sea Ice Model Project, Los Alamos National Laboratory, Los Alamos, New Mexico

\section{Jose Hernandez and David Erickson}

Computer Science and Mathematics Division, Climate Dynamics Group,

Oak Ridge National Laboratory, Oak Ridge, Tennessee

Received 10 October 2003; accepted 16 March 2004

\begin{abstract}
The authors describe planetary-scale modeling of mixed-layer dimethyl sulfide (DMS) processing and distributions, conducted at a resolution of $0.28^{\circ}$ using the Parallel Ocean Program (POP). Ecodynamic routines embedded within POP track the interactions of bacteria, multiple phytoplankton species, zooplankton, and both dissolved and detrital organics. Biogeochemistry linked to the ecosystem includes full elemental cycling for iron, nitrogen, silicon, carbon, and the portion of the sulfur cycle leading through the formation of intracellular dimethyl sulfoniopropionate (DMSP) to dissolved DMS. The two reduced sulfur compounds are emitted from the numerical plant bins at average rates proportional to the taxonomically dependent DMSP content. Within the water column they are subjected to photolysis,
\end{abstract}

*Corresponding author address: Scott Elliott, Los Alamos National Laboratory, Mail Stop D413, Los Alamos, NM 87545.

E-mail address: sme@lanl.gov 
interconversion, consumption by the bacterial pool, and loss into the troposphere. Biogeochemical species distributions were calculated synchronously with the POP ocean circulation for the period 1995-2000. The DMS concentration patterns generated agree with available global climatologies in several important aspects. Average values fall consistently between tenths to several nanomolar and remain near the low end of the interval within the oligotrophic gyres, while maxima favor the spring hemisphere. Mesoscale coupling of eddies and geocycles leads to strong variability in the $10-100-\mathrm{km}$ range that is superimposed upon local baselines. Integrated flux into the atmosphere lies toward the low end of the envelope of some recent independent calculations. This is primarily attributable to a slight but persistent underprediction of concentration. Several clear deficiencies remain in the sulfur cycle mechanism. For example, bacterial uptake and the taxonomic dependence of exudation are closely linked and together may require improved parameterization.

KEYWORDS: Dimethyl sulfide; Concentration distributions;

Biogeochemistry; Sea-air transfer; Ecodynamics; Eddy resolution; OGCM

\section{Introduction}

Among trace molecules influencing global change in the anthropocene atmosphere, dimethyl sulfide (DMS) is comparable in relevance to the major greenhouse gases (Houghton et al., 1996). It is produced by phytoplankton in large quantities, likely as a by-product of osmoregulatory and cryoprotection metabolics (Kettle et al., 1999). Subsequent transfer into the marine troposphere determines aerosol sulfate concentrations and numbers of condensation nuclei available for the formation of stratus cloud layers (Charlson et al., 1987). Paleogeochemical evidence suggests that DMS may feed back through the iron cycle during periods of either glaciation or $\mathrm{CO}_{2}$-induced warming (Watson and Liss, 1998).

Despite strong associations with terrestrial radiative forcing, however, comprehension of the oceanic DMS distribution remains largely empirical. Attempts have been made to correlate reduced sulfur with chlorophyll density (Andreae, 1986; Belviso et al., 2000; Aumont et al., 2002). These efforts have met with mixed success, and it is known from the mechanistic perspective that DMS links only weakly to generic plant distributions (Gabric et al., 1993; Chu et al., 2003). Critical time constants for the cascade of biological material through marine geochemical webs are on the order of days, so that mixed-layer turbulence should displace peaks for the major ecotracers. Moreover, laboratory evidence suggests that reduced sulfur exudation should depend heavily on plant speciation (Keller et al., 1989; Kettle et al., 1999). Biogeographical interpolation schemes are useful conceptually but do not directly incorporate local physical or biological dynamics (Longhurst, 1998; Kettle et al., 1999; Kettle and Andreae, 2000). By the same token, ecological models exist within which biogeochemical connections are made to the sulfur cycle, but they have usually been run in low dimensionality or at the regional scale (Gabric et al., 1993; van den Berg et al., 1996; Chu and Elliott, 2001). 
We are now engaged in the development of a general model for surface ocean biogeochemistry (Chu and Elliott, 2001; Chu et al., 2003) in which ecodynamically controlled elemental cycling is built systematically into the Parallel Ocean Program (POP; Dukowicz et al., 1993; Maltrud et al., 1998). Our mechanism for treating phytoplanktonic sulfate assimilation by-products has evolved in this context so that it reproduces key components of the observed DMS distribution. The present report documents recent progress in the incorporation of coupled sulfur (S) ecology-biogeochemistry into POP. We also itemize some upcoming requirements for the refinement of $S$ cycling. In particular, it may be necessary to more realistically account for both bacterial consumption and the taxonomic variation in cellular dimethyl sulfoniopropionate (DMSP) levels.

The text begins by describing the insertion of the major nutrient and structural elements $(\mathrm{N}, \mathrm{Fe}, \mathrm{Si}, \mathrm{C})$ into POP for processing. Construction of an assimilatory sulfur parameterization is then delineated, leading to processing of DMS through the mixed layer. There are only a limited number of chemically complete volatile sulfide mechanisms available to draw from (Gabric et al., 1993; van den Berg et al., 1996). The trophic hierarchy of the Gabric equations was adopted initially because it corresponds most closely with POP ecodynamics. In literature form, the Gabric mechanism is tuned in some cases to the ecological and biogeochemical dynamics of individual open-ocean bloom events. We describe a strategy of parameter relaxation that offers the potential for achieving fidelity to natural patterns at scales from the local to the global. Major steps taken so far involve recognition that 1) reduced sulfur exudation rates are, for the moment, metabolically unconstrained and hence adjustable to a degree; 2) bloom specialist plants, in general, are poor in DMSP; and 3) bacterial uptake must be strongly (biogeographically) province dependent.

Dimethyl sulfide distributions computed under these conditions are compared with large-scale climatologies (Kettle and Andreae, 2000) and also with ship cruise measurements typical of the actual database (e.g., Andreae and Raemdonck, 1983; Belviso et al., 2000). Global air-sea fluxes obtained by integration of our dynamic simulations are contrasted with calculations based upon correlations or simple extrapolation (Erickson et al., 1990; Erickson, 1993; Kettle et al., 1999; Kettle and Andreae, 2000). In the discussion section, we emphasize that important mechanistic deficiencies remain to be addressed.

\section{Biogeochemicall POP}

Our mechanism for representation of global marine geochemical processing has evolved online within POP, a $z$-coordinate ocean general circulation model. The configuration used for the simulation described here has a horizontal grid spacing of $0.28^{\circ}$ at the equator, with the meridional interval decreasing as the cosine of the latitude. While not fully eddy resolving (for which $0.1^{\circ}$ must be approached; Smith et al., 2000), this mesh represents an acceptable compromise between the needs for discrimination of mesoscale features and the mitigation of multitracer ecodynamic computational cost. The model domain extends from $77^{\circ} \mathrm{S}$ to $77^{\circ} \mathrm{N}$ so that the entire Southern Ocean is captured but the Arctic is not. There are 20 levels in the code varying from $25-\mathrm{m}$ thickness at the surface to $400 \mathrm{~m}$ in the abyss; depth is 
sufficiently resolved locally to portray major vertical mixing structures. Surface forcing is provided by the European Centre for Medium-Range Weather Forecasts (ECMWF) daily wind stress, Barnier et al.'s (Barnier et al., 1995) climatological heat fluxes, and relaxation of surface salinity to the Levitus (Levitus, 1982) climatology. More details concerning the physical model setup and results can be found in Maltrud et al. (Maltrud et al., 1998) and in Garfield et al. (Garfield et al., 2001).

Since mixed-layer nutrient cycling can be eddy driven (Chu and Elliott, 2001; Chu et al., 2003; McGillicuddy et al., 2003), ecodynamics and elemental processing comprise major applications for the fine-mode POP physics. Our strategy in designing a fully biogeochemical version has been to combine in a stepwise fashion the most desirable features of the available specialist models. Ultimately, the goal is to support an eddy-resolving simulation of whole-ocean distributions for the major geochemical drivers of global change. A short list of key tracers would include several distinct bacterial and plant classes (Maier Reimer, 1993; Doney, 1999); the animal species required to control their populations through grazing (Chai et al., 2002); major oxidation states of the elements nitrogen, iron, and silicon because they exert Liebigen control on ecology (Fasham et al., 1993; Dugdale and Wilkerson, 1998; Morel and Price, 2003); the complete carbonate system (Broecker and Peng, 1982; Maier Reimer, 1993); and the multiple trace gases that eventually force the atmospheric greenhouse either directly or indirectly (Houghton et al., 1996; Chu and Elliott, 2001). Here we expose, in chronological order as incorporated, a set of additions made to POP encompassing all of the above.

A preliminary need existed to demonstrate that fine-resolution global geocycling calculations were feasible. Satellite chlorophyll datasets offered the promise of convincing validation exercises [the Coastal Zone Color Scanner (CZCS), the Seaviewing Wide Field-of-view Sensor (SeaWiFS), and the Moderate Resolution Imaging Spectroradiometer (MODIS); see Gurney et al., 1993; Longhurst, 1998; Chavez et al., 1999; Chu et al., 2003]. Our mechanism was thus originally written to include only the nutrient elements influencing local average sea surface color (Chu and Elliott, 2001; Chu et al., 2003). Iron and nitrogen cycling were both computed globally, with the result that primary production could be well represented in the major low- and high-nitrate zones. In these calculations Aeolian dust inputs were taken from the Fung et al. (Fung et al., 2000) database. A single agglomerate plant species was patterned after the Fasham series of models, as they were configured during the decade of the 1990s (Fasham et al., 1990; Fasham et al., 1993; Sarmiento et al., 1993; Ryabchenko et al., 1997). An explicit bacterial loop was simulated, and the predicted microbial densities were in turn used to provide consumption terms relative to the direct and indirect greenhouse gases prior to their air-sea transfer (e.g., the methyl halides and nonmethane hydrocarbons; Chu and Elliott, 2001). Comparisons with sections taken from the satellite chlorophyll data are reported in Chu et al. (Chu et al., 2003). With only a few exceptions, major patterns of surface color were reproduced at all scales. Important discrepancies lay along a handful of frontal systems including the Kuroshio-Oyashio Extension. The situation is likely to improve together with the circulation physics as an even finer mesh global resolution is attained. 
Over the past year, interpretation of patch iron perturbations has motivated an introduction of more complete elemental cycling. Source/sink terms beyond the POP nitrogen and iron cycles are discussed here for the first time. Silicon processing has been added along with the diatoms as consumers (Maier Reimer, 1993; Dugdale and Wilkerson, 1998; Chai et al., 2002). Following strong nutrient injections and at the scale of a few dozen kilometers, ecology of the bloom dominators must be accurately accounted. A full carbonate (acid base) chemistry mechanism has been appended. The organic carbon harbored in the biota and in detrital particles is now treated in detail. Thermodynamic and rate parameters adopted to represent the carbon cycle are consistent with well-known conceptual and numerical models including those of Broecker and Peng (Broecker and Peng, 1982), Bacastow and Maier Reimer (Bacastow and Maier Reimer, 1990), Sarmiento and Orr (Sarmiento and Orr, 1991), Maier Reimer (Maier Reimer, 1993), and Chai et al. (Chai et al., 2002). Standards are met for the international Ocean Carbon Model Intercomparison Project (OCMIP). Phytoplankton species in the coding take up $\mathrm{Fe}, \mathrm{N}, \mathrm{Si}$, and $\mathrm{C}$ at uniform Redfield ratios as they grow. Within the nondiatom plant bin, the coccolithophorids are designated through a temperature-dependent taxonomic fraction (Maier Reimer, 1993; Houghton et al., 1996). The prymnesiophytes utilize calcium carbonate as well as the dissolved inorganic carbon (DIC) required to build soft tissue. Formation of $\mathrm{CaCO}_{3}$ is explicitly reflected in the alkalinity term, along with any negative charge loss attributable to nitrate (Maier Reimer, 1993). Connections to the overall direct/ indirect greenhouse trace gas family are retained through photolysis of dissolved organics, exudation from plants, and both chemical and biotic removal as determined at lower biogeochemical resolution (Chu and Elliott, 2001). In turn, the trace gases cross the air-sea interface in accord with a white cap-enhanced, double laminar layer model encompassing Schmidt number dependence (Erickson, 1993).

The core biogeochemistry routine (nonsulfurous and without trace gases) is summarized in Table 1 as it is now configured. Mechanistic information is organized hierarchically with the major Liebigen elements occupying the highest level, beginning with nitrogen because it functions as the primary currency. Within the nitrogen equation set, individual species are ordered roughly according to their ecological trophic status, moving from photosynthesizers through consumers and detritus. Where possible, $N$ concentration time derivatives are called upon to drive the processing of elements in other reservoirs with average compositions determining the stoichiometry (Takahashi et al., 1985). Particle sedimentation terms are omitted in the interest of clarity, but apply to all unsuspended materials and take a standard flux divergence form in the vertical. Parameters in MichaelisMenten-type $Q$ terms were selected from the recent model work of Moore et al. (Moore et al., 2002) and Chai et al. (Chai et al., 2002). What is more commonly referred to as grazing we denote by the letter $C$ here, signifying consumption. Our zooplanktonic feeding formulations mimic those in Ryabchenko et al. (Ryabchenko et al., 1997) and Chai et al. (Chai et al., 2002). The life history concepts embodied in density-dependent mortality functions follow the philosophy outlined in Ryabchenko et al. (Ryabchenko et al., 1997). Inorganic particles recycle only to a small extent within the euphotic zone. They have been ignored entirely in some 
Table la. A representation of the biogeochemistry routine employed within POP to support sulfur cycling. Derived from sources including Maier Reimer (Maier Reimer, 1993), Fasham et al. (Fasham et al., 1993), Ryabchenko et al. (Ryabchenko et al., 1997), Moore et al. (Moore et al., 2002), and Chai et al. (Chai et al., 2002). A transition from surface to generic thermocline processing is set between 110 and $135 \mathrm{~m}$. Upper-level decay rates often correspond with pure linear losses at depth such that the two could be combined. We have elected for the moment to retain consistency with euphotic zone $\mathrm{N}$ currency models for both parameters and algorithms (e.g., Sarmiento et al., 1993). Note that the D may embody life history features including overwintering strategies.

\begin{tabular}{|c|c|c|c|}
\hline Element & Form & SMS (surface layers) & $\operatorname{SMS}[f(z)]$ \\
\hline \multirow[t]{10}{*}{$\mathrm{N}$} & $\mathrm{P}_{\mathrm{Non}}$ & $\left(1-\gamma_{\text {Non }}\right) J_{\text {Non }}\left(Q^{\mathrm{Nit}}{ }_{\text {Non }}+Q_{\text {Non }}^{\mathrm{Am}}\right) Q_{\text {Non }}^{\mathrm{Fe}} \mathrm{P}_{\text {Non }}-C_{\text {Mic }}^{\mathrm{Non}}-D_{\text {Non }}$ & $-\lambda_{\text {Non }} \mathrm{P}_{\text {Non }}$ \\
\hline & $P_{\text {Diat }}$ & $\left(1-\gamma_{\text {Diat }}\right) J_{\text {Diat }}\left(Q^{\mathrm{Nit}}{ }_{\text {Diat }}+Q^{\mathrm{Am}}{ }_{\text {Diat }}\right) Q_{\text {Diat }}^{\mathrm{Fe}} Q_{\text {Diat }}^{\mathrm{Si}} \mathrm{P}_{\text {Diat }}-C^{\text {Diat }}{ }_{\text {Mes }}-D_{\text {Diat }}$ & $-\lambda_{\text {Diat }} \mathrm{P}_{\text {Diat }}$ \\
\hline & $\mathrm{Z}_{\text {Mic }}$ & $\gamma_{\text {Mic }}\left(\Sigma C_{\text {Mic }}\right)-C_{\text {Mes }}^{\text {Mic }}-D_{\text {Mic }}$ & $-\lambda_{\text {Mic }} Z_{\text {Mic }}$ \\
\hline & $\mathrm{Z}_{\mathrm{Mes}}$ & $\gamma_{\mathrm{Mes}}\left(\Sigma C_{\mathrm{Mes}}\right)-D_{\mathrm{Mes}}$ & $-\lambda_{\mathrm{Mes}} Z_{\mathrm{Mes}}$ \\
\hline & B & $U^{\mathrm{Dom}}+U^{\mathrm{Am}}-C_{\text {Mic }}^{\mathrm{B}}-D_{\mathrm{B}}$ & $-\lambda_{\mathrm{B}} \mathrm{B}$ \\
\hline & $\mathrm{N}_{\mathrm{Nit}}$ & $-J_{\text {Non }} Q^{\mathrm{Nit}{ }_{\text {Non }}^{\prime}} Q_{\text {Non }}^{\mathrm{Fe}} \mathrm{P}_{\text {Non }}-J_{\text {Diat }} Q^{\mathrm{Nit}{ }^{\prime}}{ }_{\text {Diat }} Q_{\text {Diat }}^{\mathrm{Fe}} Q_{\text {Diat }}^{\mathrm{Si}} \mathrm{P}_{\text {Diat }}$ & $+\lambda_{\mathrm{Am}} \mathrm{N}_{\mathrm{Am}}$ \\
\hline & $\mathrm{N}_{\mathrm{Am}}$ & $\begin{array}{l}D_{\text {Mic }}+\varepsilon D_{\text {Mes }}+D_{\mathrm{B}}-J_{\text {Non }} Q_{\text {Non }}^{\mathrm{Am}} Q_{\text {Non }}^{\mathrm{Fe}} \mathrm{P}_{\text {Non }}-J_{\text {Diat }} Q_{\text {Diat }}^{\mathrm{Am}} Q_{\text {Diat }}^{\mathrm{Fe}} Q_{\text {Diat }}^{\mathrm{Si}} \\
\mathrm{P}_{\text {Diat }}-U^{\mathrm{Am}}\end{array}$ & $\Sigma \lambda \mathrm{N}-\lambda_{\mathrm{Am}} \mathrm{N}_{\mathrm{Am}}$ \\
\hline & $\mathrm{N}_{\text {Dom }}$ & $\begin{array}{l}\gamma_{\text {Non }} J_{\text {Non }}\left(Q^{\mathrm{Nit}{ }_{\text {Non }}}+Q^{\mathrm{Am}}{ }_{\text {Non }}\right) Q^{\mathrm{Fe}}{ }_{\text {Non }} \mathrm{P}_{\text {Non }}+\gamma_{\text {Diat }} J_{\text {Diat }}\left(Q^{\text {Nit' }}{ }_{\text {Diat }}+Q^{\mathrm{Am}}{ }_{\text {Diat }}\right) \\
Q_{\text {Diat }}^{\mathrm{Fe}} Q_{\text {Diat }}^{\mathrm{Si}} \mathrm{P}_{\text {Diat }}+\delta D_{\text {Mes }}+D_{\text {NSP }}-U^{\text {Dom }}\end{array}$ & $-\lambda_{\text {Dom }} N_{\text {Dom }}$ \\
\hline & $\mathrm{N}_{\mathrm{SP}}$ & $\left(1-\gamma_{\mathrm{Mic}}\right)\left(\Sigma C_{\mathrm{Mic}}\right)+D_{\mathrm{Non}}-D_{\mathrm{NSP}}-C^{\mathrm{NSP}}{ }_{\mathrm{Mes}}$ & $-\lambda_{\mathrm{NSP}} \mathrm{N}_{\mathrm{SP}}$ \\
\hline & $\mathrm{N}_{\mathrm{LP}}$ & $\left(1-\gamma_{\mathrm{Mes}}\right)\left(\Sigma C_{\mathrm{Mes}}\right)+(1-\varepsilon-\delta) D_{\mathrm{Mes}}+D_{\text {Diat }}$ & $-\lambda_{\mathrm{NLP}} \mathrm{N}_{\mathrm{LP}}$ \\
\hline $\mathrm{Fe}$ & $\mathrm{FeL}_{\mathrm{n}}$ & $R_{\mathrm{Fe}}\left[\mathrm{SMS}\left(\mathrm{N}_{\mathrm{Nit}}\right)+\mathrm{SMS}\left(\mathrm{N}_{\mathrm{Am}}\right)\right]-S c$ & Left, pseudo \\
\hline \multirow[t]{2}{*}{$\mathrm{Si}$} & $\mathrm{Si}(\mathrm{OH})_{4}$ & $-R_{\mathrm{Si}}$ Source $\left(\mathrm{P}_{\text {Diat }}\right)+\lambda_{\mathrm{SiLP}} \mathrm{Si}_{\mathrm{LP}}$ & See left \\
\hline & $\mathrm{Si}_{\mathrm{LP}}$ & $R_{\mathrm{Si}} \operatorname{Sink}\left(\mathrm{P}_{\mathrm{Diat}}\right)-\lambda_{\mathrm{SiLP}} \mathrm{Si}_{\mathrm{LP}}$ & See left \\
\hline \multirow[t]{3}{*}{$\mathrm{Ca}$} & $\mathrm{Ca}^{2+}$ & $-F_{\mathrm{Coc}} R_{\mathrm{Ca}}$ Source $\left(\mathrm{P}_{\mathrm{Non}}\right)+\lambda_{\mathrm{CaSP}} \mathrm{Ca}_{\mathrm{SP}}$ & See left \\
\hline & $\mathrm{Ca}_{\mathrm{SP}}$ & $\operatorname{Sink}\left(\mathrm{Ca}^{2+}\right)-\lambda_{\mathrm{CaSP}} \mathrm{Ca}_{\mathrm{SP}}$ & See left \\
\hline & Alk & $2 \mathrm{SMS}\left(\mathrm{Ca}^{2+}\right)-\mathrm{SMS}\left(\mathrm{N}_{\mathrm{Nit}}\right)$ & See left \\
\hline $\mathrm{C}$ & DIC & $R_{\mathrm{C}}\left[\mathrm{SMS}\left(\mathrm{N}_{\mathrm{Nit}}\right)+\mathrm{SMS}\left(\mathrm{N}_{\mathrm{Am}}\right)\right]+\mathrm{SMS}\left(\mathrm{Ca}^{2+}\right)$ & See left \\
\hline $\mathrm{O}$ & $\mathrm{O}_{2}$ & $R_{\mathrm{O}}\left[\mathrm{SMS}\left(\mathrm{N}_{\mathrm{Nit}}\right)+\mathrm{SMS}\left(\mathrm{N}_{\mathrm{Am}}\right)\right]$ & See left \\
\hline
\end{tabular}

of our runs with resetting at the lower boundary proving sufficient to sustain remineralization. Effects upon the dimethyl sulfide distribution are minimal.

The ecodynamics are currently computed synchronously (or "online") in step with POP, though the overall biogeochemistry is not yet permitted to influence physics through effects on water column radiative transfer. The lower limit for biogeochemistry modeling was set at the start of the seventh model layer, corresponding to $185-\mathrm{m}$ depth. The boundary was established so that over most of the ocean, elemental cycling effects could permeate stratified waters within a few years ( $\mathrm{Li}$ et al., 1984). Biogeochemical conditions are fixed as annual averages along the deepest nonsimulated surface, according to standard climatologies (e.g., Broecker et al. 1982; Levitus et al., 1993; see online at http://www.nodc.noaa.gov/ OC5/WOA98F/open_1st.html). Fields are initialized in the thermocline and mixed layer based on the same sources. Complete biology modeling begins on 1 January 1995 , and a rough planetary steady state is attained within a few years (see the conclusions of Sarmiento et al., 1993 and Chu et al., 2003). Effects of the 1997/98 El Niño are effectively bracketed, but response of DMS to the Southern Oscillation 
Table 1b. Explanation of symbols and references. C02: Chai et al. (2002), F93: Fasham et al. (1993), F00: Fung et al. (2000), J03: Jiang et al. (2003), LW99: Lefevre and Watson (1999), MR93: Maier Reimer (1993), M02: Moore et al. (2002), PT73: Parsons and Takahashi (1973), R97: Ryabchenko et al. (1997), S93: Sarmiento et al. (1993), and T85: Takahashi et al. (1985).

\begin{tabular}{|c|c|c|}
\hline Symbol & Reference & Notes \\
\hline SMS & S93, F93 & Source minus sink, grid cell internal continuity \\
\hline Non & PT73 & $\begin{array}{l}\text { Nondiatoms (all other plant species, except diazotrophs that are not } \\
\text { treated here) }\end{array}$ \\
\hline$\gamma_{\mathrm{P}}$ & S93, R97 & Exudation, order $5 \%$ \\
\hline$J_{\text {Non }}$ & $\mathrm{C} 02, \mathrm{~S} 93$ & Exponential form, maximum growth tailored to low/mid-latitudes \\
\hline$J_{\text {Diat }}$ & M02, C02 & Approximately $1.5 J_{\text {Non }}$ in most locations \\
\hline$Q^{\mathrm{N}}{ }_{\text {Non }}$ & M02, C02 & Intermediate ammonia $\mathrm{K}$ value from Chai group \\
\hline$Q_{\text {Diat }}^{\mathrm{N}}$ & $\mathrm{M} 02, \mathrm{C} 02$ & Ammonia $\mathrm{K}(\mathrm{Diat})$ to $\mathrm{K}(\mathrm{Non})$ ratio from Moore group \\
\hline '(prime) & $\mathrm{C} 02$ & Inhibition of nitrate uptake consistent with ammonia half saturation \\
\hline$Q^{\mathrm{Fe}}$ & M02 & K Order $100 \mathrm{pM}$ \\
\hline$Q^{\mathrm{Si}}$ & $\mathrm{C} 02, \mathrm{M} 02$ & K Order $1 \mu \mathrm{M}$ \\
\hline$D_{\text {Non }}$ & R97 & Density dependent mortality (decay) \\
\hline$D_{\text {Diat }}$ & R97, M02 & See $D_{\text {Non }}$ \\
\hline$\lambda_{\text {Sus }}$ & S93 & Regeneration at order 10 days for dissolved or suspended species \\
\hline Mic,Mes & $\mathrm{C} 02$ & Micro- and Mesozooplankton \\
\hline$\gamma_{\mathrm{Z}}$ & F93, S93, R97 & Assimilation or (1-fecal), averaged over global $Z$ populations \\
\hline$C_{\text {Mic }}$ & $\mathrm{R} 97, \mathrm{C} 02$ & Resources are Non, B; $C$ here is consumption, often referred to as $G$ \\
\hline$C_{\text {Mes }}$ & C02, R97 & Midlevel resources are Diat, Mic, SP \\
\hline$D_{\text {Mic }}$ & $\mathrm{R} 97, \mathrm{C} 02$ & Decay or excretion, for Mic predation is $C$ \\
\hline$D_{\text {Mes }}$ & $\mathrm{R} 97, \mathrm{C} 02$ & Processing by fish negligible but is closed here per global average \\
\hline$U$ & R97 & For simplicity B ammonia uptake implies photosynthesis \\
\hline$D_{\mathrm{B}}$ & S93, R97 & Excretion \\
\hline$\varepsilon$ & S93, R97 & Zooplankton decay to ammonia via predation \\
\hline$\delta$ & R97 & Fraction of zooplankton loss to Dom as mediated by predation \\
\hline$D_{\mathrm{NSP}}$ & R97 & Breakdown of small organic particles \\
\hline$\lambda_{\text {Part }}$ & S93, J03, MR93 & Adjust to match observed scale depths or $T$ dependence \\
\hline$R_{\mathrm{Fe}}$ & F00 & Organic $\mathrm{Fe} / \mathrm{N}$ ratio order $1 / 50,000$ on average HNLC worldwide \\
\hline Sc & M02 & Scavenging at 6 months $<600 \mathrm{pM}, 1$ month $>600 \mathrm{pM}$ \\
\hline Pseudo & F00, LW99 & Replace $S c<600 \mathrm{pM}$ by pseudo 1 st order relax to $1 / 4 R_{\mathrm{Fe}} \mathrm{N}_{\mathrm{Nit}} \tau=f(z)$ \\
\hline$R_{\mathrm{Si}}$ & MR93, C02 & Roughly unity, ignore iron stress \\
\hline$F_{\mathrm{Coc}}$ & MR93 & $T$-dependent fraction of coccolithophorids among nondiatoms \\
\hline$R_{\mathrm{Ca}}$ & IPCC96 & Roughly unity relative to organic carbon \\
\hline$V_{\mathrm{SP}, \mathrm{LP}}$ & S93, J03 & All small particles sink at $10 \mathrm{~m}$ day $^{-1}$, large at $40 \mathrm{~m}_{\text {day }}{ }^{-1}$ \\
\hline$R_{\mathrm{C}}$ & T85, MR93 & Organic $\mathrm{C} / \mathrm{N}$ is close to 7 \\
\hline$R_{\mathrm{O}}$ & T85, MR93 & Delta $\mathrm{O}_{2}$ order -10 \\
\hline
\end{tabular}

only will be documented later in a report we have planned focusing on total (biogeochemical) interannual variability.

Concentration resetting within the upper ocean implies a potential sacrifice in fidelity in areas where mixing depths may drop below model boundaries in the winter. One expectation would be that nutrient transport is then overestimated because dilution processes are superceded. The effect will be difficult to quantify until full-depth biogeochemistry has been incorporated and coupled to the sulfur cycle. However, it is likely to be restricted to zones of deepest winter mixing penetration and especially the central, high North Atlantic (Longhurst, 1998). Our 
plan is to extend the POP geocycling well below the main thermocline in near-term runs. It will then be possible to compare with simulations based upon fixed shoal concentration conditions.

\section{The sulfur cycle}

Reduced sulfur processing has been considered continually across this development sequence as a special case, due to the unique Earth system standing of dimethyl sulfide (Houghton et al., 1996). The S geocycling is decoupled from marine ecology, being neither biolimited nor biolimiting (Broecker and Peng, 1982; Andreae, 1986). The greatest influence on organisms is in fact likely to follow from aerosol-cloud feedbacks (Charlson et al., 1987; Watson and Liss, 1998). It is thus unnecessary to track dissolved sulfate as a source pool. A set of increasingly complex volatile sulfide mechanisms has been tested within biogeochemical POP over a period of several years. Initially, we applied simple production and loss terms in the coarse mode to reproduce measured depth profiles (e.g., Andreae, 1986; Kiene and Bates, 1990; Houghton et al., 1996). Roughly in parallel with the introduction of DMS into fine-resolution POP, the original Gabric mechanism was adopted inclusive of DMSP (Gabric et al., 1993; Gabric et al., 1995). Ecodynamic binning corresponded closely with the Fasham-based system already evolving in our routines. We quickly found in low-dimensionality studies, however, that the Gabric reaction list tended to underestimate DMS concentrations in stratified waters (Chu and Elliott, 2001; Chu et al., 2003). The offsets were most pronounced in the centers of the oligotrophic gyres. Our interpretation has been that the specified production/removal parameters are designed primarily for the representation of bloom conditions.

An effort was embarked upon to relax the reaction set away from bloom dependence such that it would extend to highly variable conditions experienced globally. A community speculation regarding taxonomic dependence has been that species in upwelling zones favor nitrogen-containing osmolytes (e.g., glycine betaine; Andreae, 1986; Kettle et al., 1999). Tabulations show that the intracellular DMSP content of some diatoms may be considered low on a relative basis (Gabric et al., 1993). In our mechanisms, exudation rates for DMS and the propionate were thus set proportional to the cell sulfide content, expressed as an oxidation state linked, pseudo-Redfield ratio. Silicate secretors were distinguished from all other classes of organism, and the latter in turn were aggregated. During model blooms the diatoms constitute a major portion of plant biomass (Longhurst, 1998; Moore et al., 2002) so that a DMS peak undershoot resulted. However, actual release fluxes from cells are poorly constrained by experiment and therefore entail a degree of flexibility. Effective intracellular residence times of the sulfide and propionate were adjusted downward relative to the round values quoted in the works of Gabric and others (i.e., toward faster exudation). At this point in the relaxation procedure it was found that central-ocean concentrations remained too low. The Gabric reaction list provides only for global-average bacterial consumption, with a time constant of around 1 day. The figure is consistent with depth profile monitoring conducted by the Max Planck group (Andreae, 1986) or Kiene and Bates (Kiene and Bates, 1990). However, microbial ecology reviews and a few large-scale models, which 
include the bacterial loop (Fasham et al., 1993; Chu et al., 2003), demonstrate that picoplanktonic cell densities must vary by several orders of magnitude across biogeographical regimes (Longhurst, 1998). Microphysical considerations including those regarding diffusion control dictate that uptake should have strong latitudinal dependence and should also drop moving away from the continental shelf. In the simulations described, DMS and DMSP bacterial consumption constants were reduced somewhat (removal times raised) as microbial densities fall toward the gyre centers.

The sulfur cycle incorporated for runs reported here is listed in Table 2, which refers directly to controlling variables from the ecodynamics mechanism. We include explicit values for all rates and like parameters because many are new to the literature. Differences relative to the foundation model (Gabric et al., 1993) reflect the relaxation adjustments. Note, for example, an augmentation of the exudation rate constants. Variation in the microbe-related parameter set has been restricted here to the range indicated by sulfur model sensitivity tests. The span of DMS consumption time constants is less than a power of 10 , and globally all values remain in the vicinity of hours to days. Changes introduced relative to the earlier work improve our simulations of DMS concentration patterns substantially. However, it is clear that further adjustments are forthcoming. The laws of microphysical fluid dynamics and enzyme kinetics as applied to planktonic material processing suggest that over large areas of the ocean, the dependence of in situ trace gas removal time should approach first order against the bacteria (Sarmiento et al., 1993; Jumars, 1993; Mann and Lazier, 1996); with reference to Table 2, pseudo removal rate constants $k_{\mathrm{B}}$ are ultimately expected to take the form $f\left(\mathrm{~B}^{n}\right)$, where $n$ is close to 1 . Verification (elucidation) of the exponent and full functionality will be essential for long-term, coupled ocean-atmosphere sulfur cycle simulations.

\section{Results}

After several years of spinup of the biogeochemistry starting from January 1995, we confirm by examination of many geocycling variables that the model approaches a global biotic steady state. In Figure 1 the associated DMS distribution is presented as an average over the year 1999 (which may be characterized as normal in terms of the ENSO index). Eddy variability is apparent along with overall basin-scale patterns, and it becomes even more pronounced in single time step snapshots or over short-term distributions. In Figure $1 \mathrm{~b}$ the model values are collapsed into zonal averages. Gyre systems and the equatorial divergence stand out, but the range extends only from tenths to several nanomolar. The observed synoptic evenness of the global distribution is thus captured (Kettle et al., 1999; Kettle and Andreae, 2000), but in total our dimethyl sulfide concentrations underpredict measurements by perhaps half a nanomolar. In waters experiencing extreme winter convection (Longhurst, 1998), restoring at the lower boundary may be responsible for a portion of the difference. As for other biogeochemical quantities, sulfide concentrations are reset near $200 \mathrm{~m}$. There may be artificial reductions where vertical cells penetrate more deeply. Temporal averages near the Poles, however, are necessarily weighted toward bloom seasons. 
Table 2a. Sulfur cycle mechanism attached within POP to the ecodynamics of Table 1. The list is similar to equations outlined in Chu et al. (Chu et al., 2003) but has been adjusted to accommodate multiple phytoplankton classes and a certain amount of variability in bacterial uptake rates. Untransported quantities are included at the list opening for clarity. The sulfoniopropionate exists in plant tissues as a product of sulfate assimilation and coproduct with amino acid synthesis (Andreae, 1986). Sulfate itself is discussed in the text. The free forms dimethyl sulfide and DMSP are advected and diffused along with other biogeochemical tracers. Values from Table 1 are imported here as nitrogen concentrations.

\begin{tabular}{cllc}
\hline Element & Form & \multicolumn{1}{c}{ SMS (surface layers) } & SMS[f(z)] \\
\hline $\mathrm{S}$ & $\mathrm{DMSP}_{\text {Non }}$ & Implicit to maintain $R_{\mathrm{S}, \text { Non }} \mathrm{P}_{\text {Non }}$ & All as left \\
& DMSP $_{\text {Diat }}$ & Implicit to maintain $R_{\mathrm{S}, \text { Diat }} \mathrm{P}_{\text {Diat }}$ & \\
& $\mathrm{SO}_{4}^{2-}$ & 0 (Present in excess as a component of salinity $)$ & \\
$\mathrm{DMS}$ & $k_{\mathrm{P}}\left(\mathrm{DMSP}_{\text {Non }}+\mathrm{DMSP}_{\text {Diat }}\right)+k_{\text {Conv }} \mathrm{DMSP}\left(k_{\mathrm{B}}+k_{\mathrm{Ph}}\right) \mathrm{DMS}$ & \\
& $\mathrm{DMSP}$ & $k_{\mathrm{P}}\left(\mathrm{DMSP}_{\text {Non }}+\mathrm{DMSP}_{\text {Diat }}\right)+k_{\mathrm{Z}}\left(\Sigma R_{\mathrm{S}, \mathrm{Z}} \mathrm{Z}\right)-\left(k_{\text {Conv }}+k_{\mathrm{B}}\right) \mathrm{DMSP}$ & \\
\hline
\end{tabular}

Furthermore, the bias is pervasive, cutting across diverse provinces. In nextgeneration POP runs the arbitrary plant production constants will be adjusted upward to minimize the concentration discrepancy at low to moderate latitudes.

Most mixed-layer dimethyl sulfide concentration data are obtained by direct ship-based sampling. Because of the molecule's Earth system significance, there have been dozens of extended tracks published in recent decades. Nonetheless, basin-sized stretches of open-ocean surface water remain underinvestigated. Compilers Kettle et al. (Kettle et al., 1999) found, as others had before, that correlations with the major oceanographic variables are weak. Properties that have been tested in this regard include temperature, salinity, chlorophyll content, BruntVäisälä frequency, biological production expressed in its various forms, and the $f$ ratio. Kettle and company ultimately relied upon an interpolation and extrapolation scheme connected with ecosystem biogeographic breakdowns (Longhurst, 1998). Updating quickly became necessary as new data were published regarding the northern oceans (Kettle and Andreae, 2000). A useful but imperfect portrait of global patterns has resulted from the effort. It constitutes the best overview

Table 2b. Explanation of symbols and references. A86: Andreae (1986), C03: Chu et al. (2003), G93: Gabric et al. (1993), K89: Keller et al. (1989).

\begin{tabular}{|c|c|c|}
\hline Symbol & Reference & Notes \\
\hline Non & A86 & For the $S$ cycle, taxa denote an intracellular reduced sulfur content \\
\hline$R_{\mathrm{S}, \text { Non }}$ & K89,G93 & 0.13, from the measured $\mathrm{S}(\mathrm{DMSP}) / \mathrm{N}$ mass ratio 0.3 \\
\hline$R_{\mathrm{S}, \text { Diat }}$ & K89,G93 & 0.013 , from the measured $\mathrm{S}(\mathrm{DMSP}) / \mathrm{N}$ mass ratio 0.03 \\
\hline$k_{\mathrm{P}}$ & This work & 0.04 day $^{-1} ; \mathrm{G} 93 \times 4$ \\
\hline$k_{\text {Conv }}$ & $\mathrm{G} 93, \mathrm{C} 03$ & Interconversion at 0.5 day $^{-1}$ so that most DMSP routes to $B$ \\
\hline$k_{\mathrm{B}}$ & This work & 1.0 day $^{-1}$ from G93 unless $B(N)<0.01 \mu \mathrm{M}$, then 0.2 DMS or 0.7 DMSP \\
\hline$k_{\mathrm{Ph}}$ & G93,C03 & 0.5 exp(-optical depth) day ${ }^{-1}$ \\
\hline$k_{\mathrm{Z}}$ & This work & 0.04 day $^{-1} ; \mathrm{G} 93 \times 4$ \\
\hline$R_{\mathrm{S}, \mathrm{Z}}$ & This work & Treated as weighted average of consumable content \\
\hline
\end{tabular}


1a - Annual surface DMS ( $\mathrm{nmol}$ )
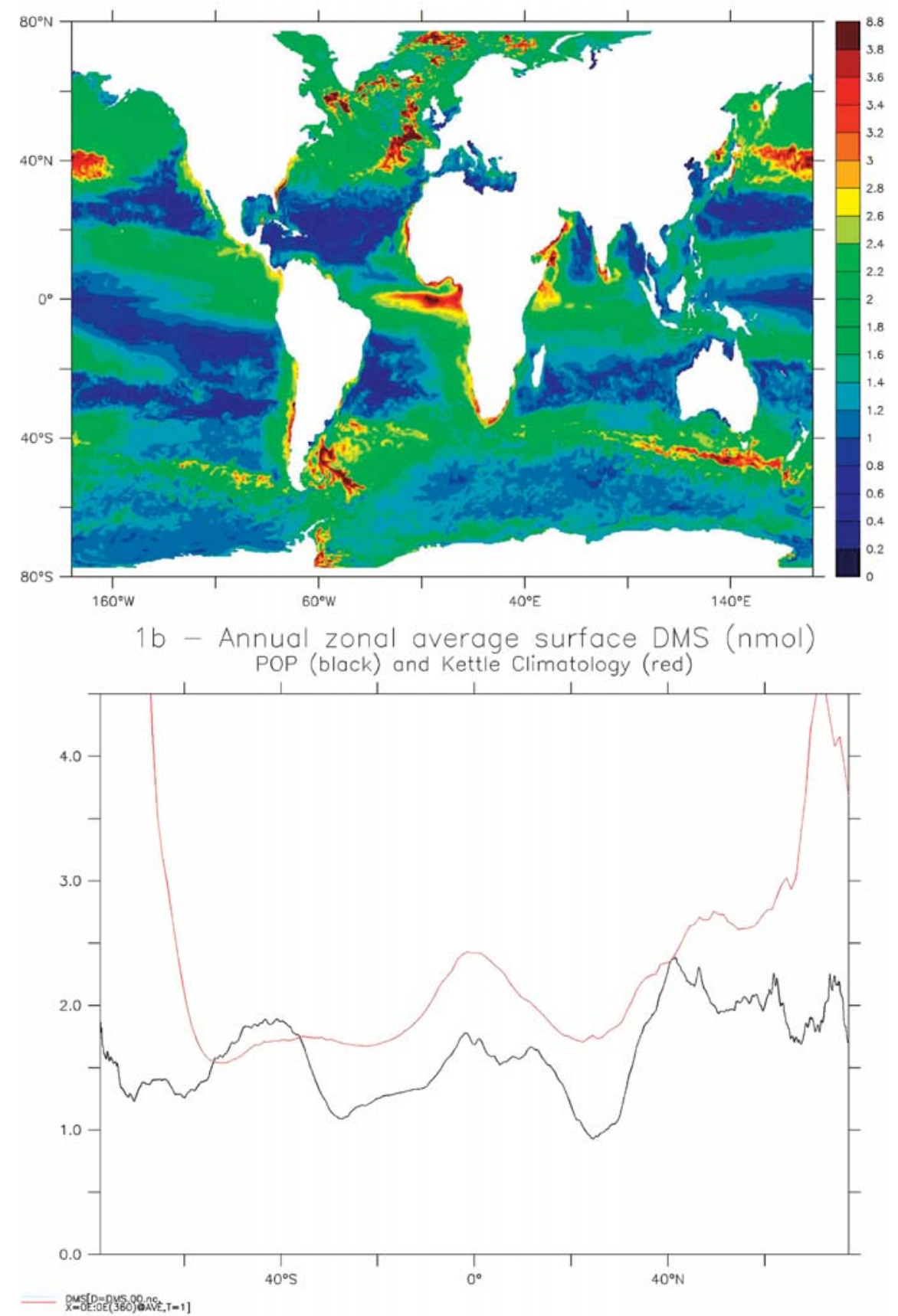

Figure 1. Annual average DMS concentrations ( $\mathrm{nM}$ ) derived from biogeochemical POP for 1999 in (a) global projection and (b) zonal average. Updated information from the Kettle series is superimposed in the second plot (Kettle et al., 1999; Kettle and Andreae, 2000). 


\section{Annual Kettle climatology surface DMS ( $\mathrm{nmol}$ )}

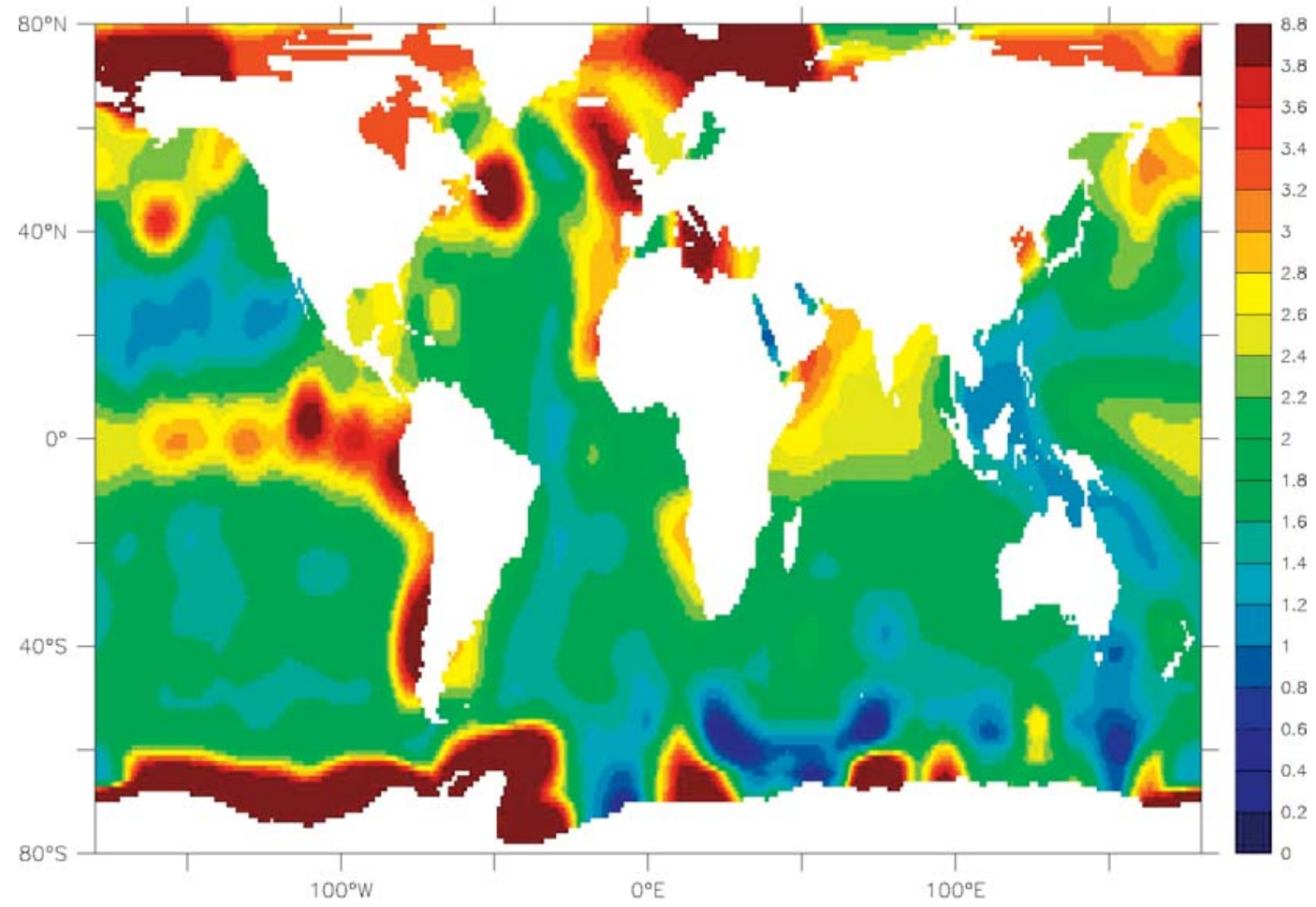

Figure 2. Annual average DMS concentration patterns (nM) in the major compilation/climatology (Kettle et al., 1999; Kettle and Andreae, 2000). Interpolation follows the biogeographical province boundaries of Longhurst (Longhurst, 1998).

available and will be taken here as a point of departure for validation of our fineresolution simulations.

Data from the Kettle interpolation are provided in Figures $1 \mathrm{~b}$ and 2 for comparison with the model results. The coarse nature of the provincing and smoothing procedures is revealed, but major patterns are quite encouraging. Biogeochemical POP picks up many key properties of the integrated observation set. Particular successes may be cited in the central northern Atlantic and Pacific, and with regard to eastern basin upwellings in the Southern Hemisphere. The most obvious discrepancy in the planetary-scale result lies alongside Antarctica. This may be related either to sea-ice biophysical interactions not yet dealt with in the model or to the need for a specialized treatment of the local phytoplankton taxonomy. Equatorial phasing is also problematic. Pacific and Atlantic concentrations appear to be too low and high, respectively.

In Figure 3 a differencing analysis is presented for the finely resolved POP results relative to the Kettle and Andreae (Kettle and Andreae, 2000) annual values. Similar calculations performed after averaging model output to the climatological grid gave an image that was essentially indistinguishable. The red 


\section{Annual surface DMS difference (Kettle-POP) (nmol)}

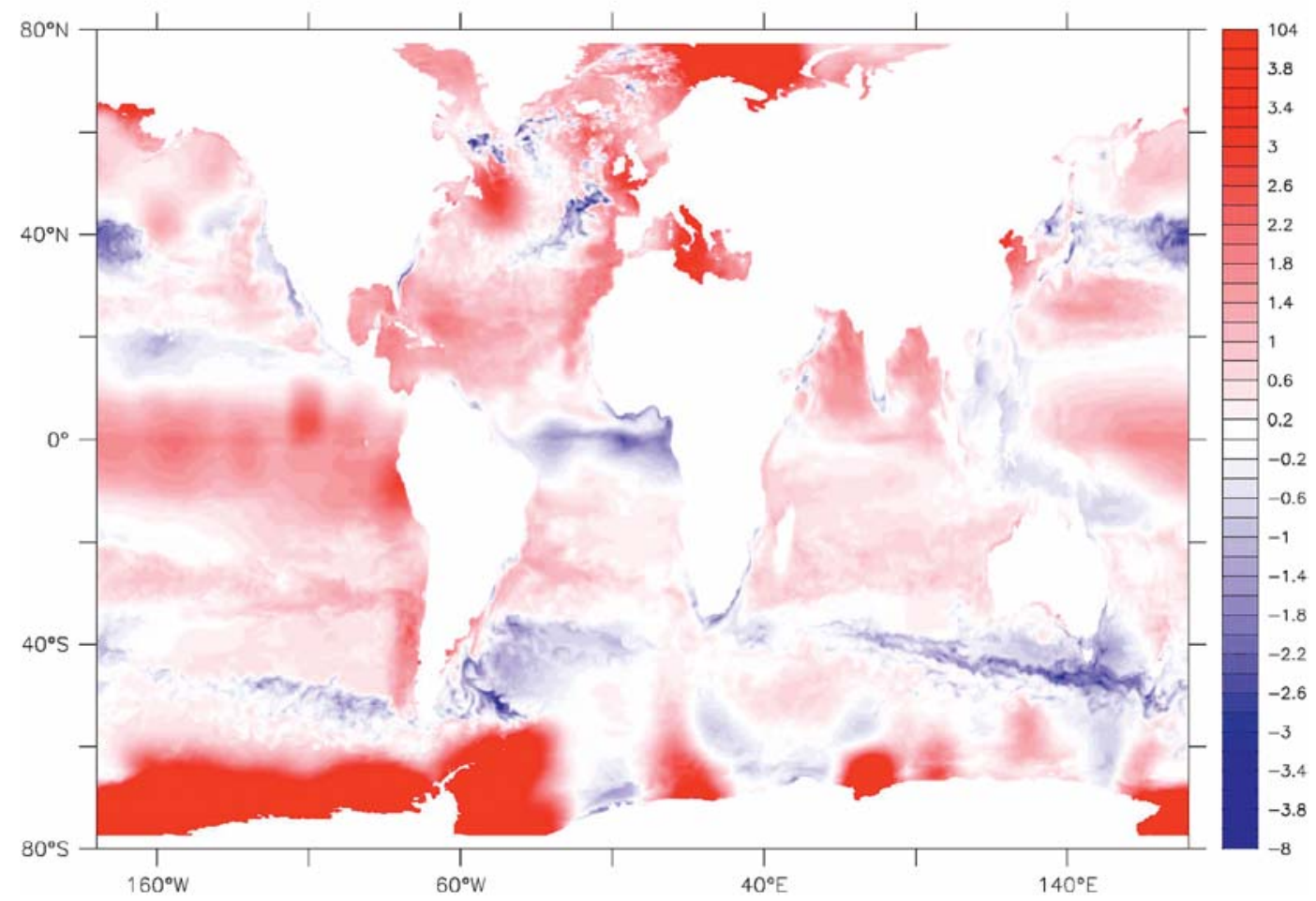

Figure 3. Climatology to model differencing plot; Kettle interpolations minus biogeochemical POP results averaged over 1999 as in Figure 1 a. (Units: $\Delta \mathrm{nM}$ ).

tones in Figure 3 indicate model concentrations on the low side relative to the interpolated dataset. The extreme Southern Ocean problem is thus accented. The area remains an undersampled regime from the dimethyl sulfide standpoint, so that the database itself may be called into question. In midlatitude coastal regimes the mismatch may be on the order of several nanomolar; refer, for example, to the China Sea and to the Grand Banks off Newfoundland. River delta, transition, and shelf zones are not yet adequately represented in biogeochemical POP. Fundamental geocycling as it has so far been developed does not include lithospheric or sediment interactions. We are hoping to incorporate margin biogeochemistry within a few years. Coastal arguments may be applicable to portions of the Antarctic discrepancy as well. Open-ocean concentrations exceed those in the climatology most obviously along much of the Antarctic circumpolar front, in the tropical Atlantic and over the Kuroshio-Oyashio $(\mathrm{K}-\mathrm{O})$ Extension. In the $\mathrm{K}-\mathrm{O}$ case this is likely related to problems with separation of the boundary current from Japan-in midresolution POP it generally occurs too far to the north. Tropical Atlantic overprediction may derive from an excess of upwelling that has been documented for the physical model. Along the Pacific divergence, production is extremely sensitive to uncertain atmospheric iron inputs and subsequent 

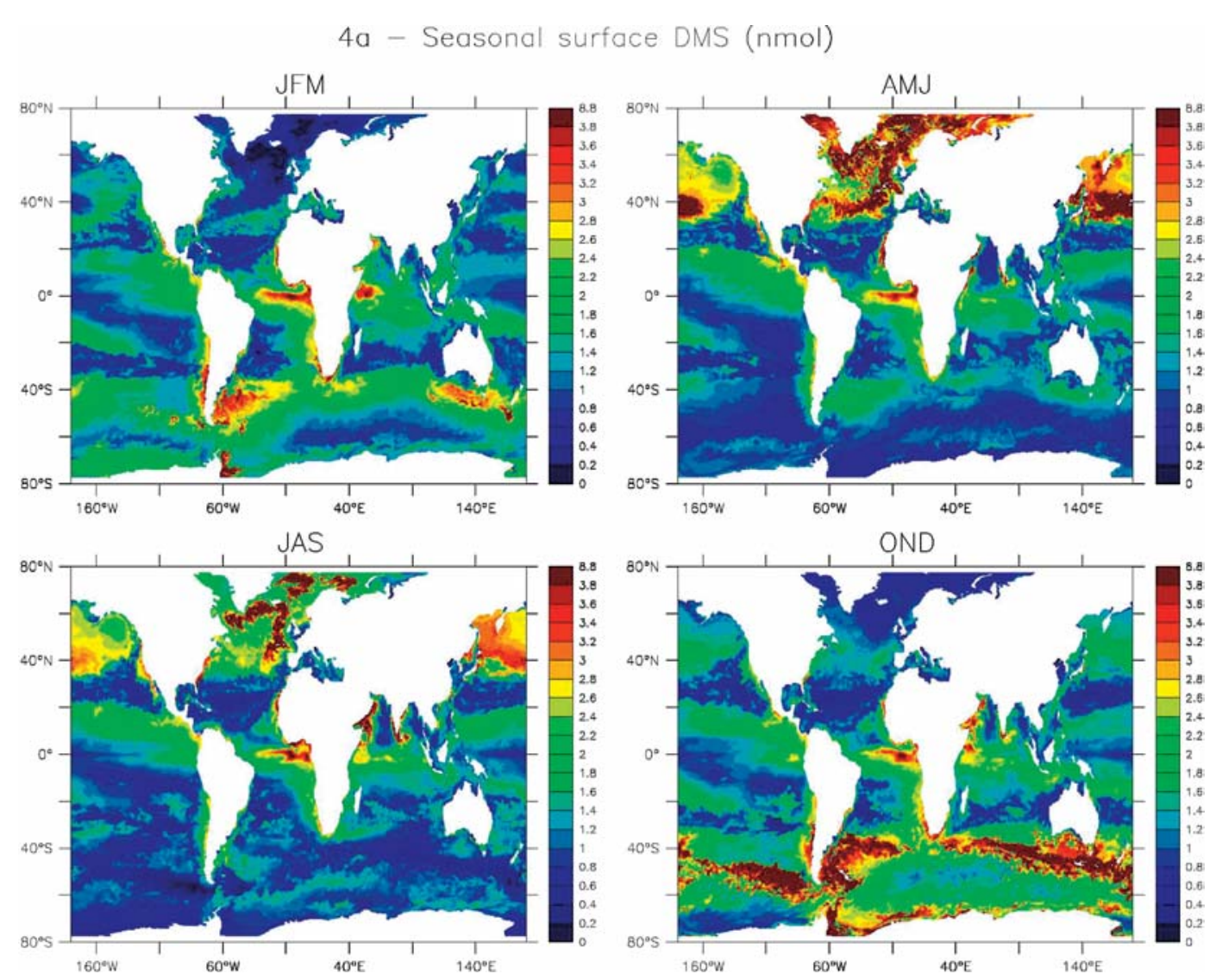

Figure 4. Seasonal averages for DMS concentrations in the POP model (nM), displayed both (a) globally and $(b)$ in zonal integration with updated Kettle results included. The year is 1999.

processing of the trace metal. The few sensitivity tests that we have been able to conduct demonstrate that chlorophyll in the equatorial regions is strongly dependent upon inorganic iron lifetime. The value was fixed at 6 months for current calculations (F. Chavez 2004, personal communication). In general over the planetary mixed layer, calculated DMS concentrations fall within a nanomolar of climatological values.

Seasonal averages from POP results are offered in Figures $4 a, b$, mirroring the setup in Figure 1 with zonal climatological averages appended. The classic tendency is exhibited for large-scale phytoplanktonic blooms to track the solar zenith angle. This is also evidenced in animations we have performed, but with eddy-driven variability inclusive. Winter injects nitrogen into the mixed layer via convective overturn, spring traps nutrients above the seasonal thermocline, and the biological pump ultimately removes the material as organics. By contrast, much less activity is apparent within the central-ocean downwelling zones. In our simulations the wind-driven iron cycle is also included and modulates biogeochemical behaviors under high nitrate, low chlorophyll conditions (HNLC; Fung et al., 2000; Moore et al., 2002). The high-latitude seasonal pulsing of 
$4 \mathrm{~b}$ - Zonal average seasonal surface DMS (nmol)
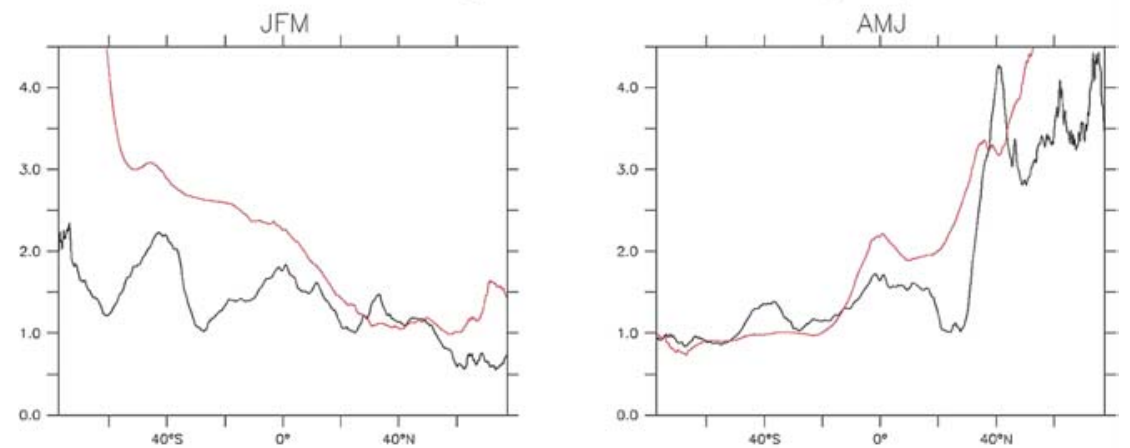

JAS
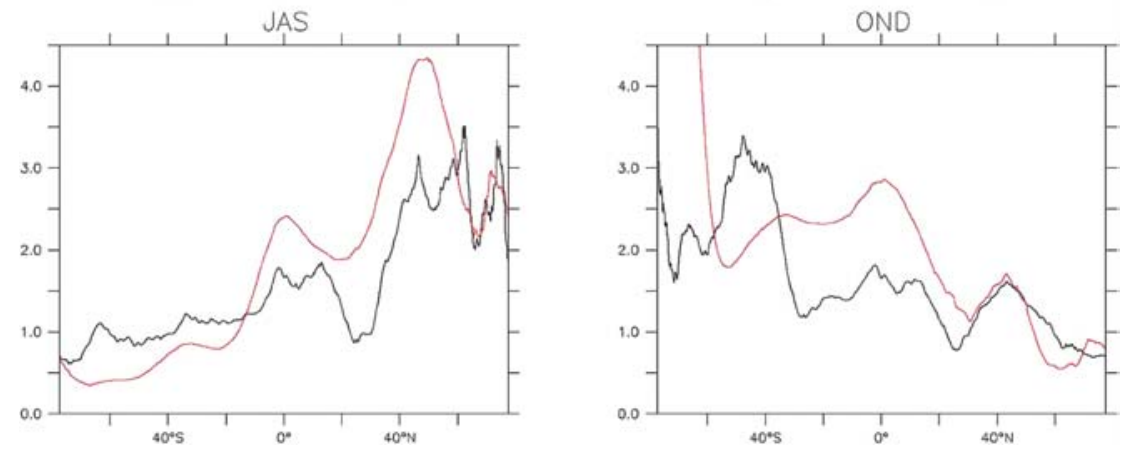

Figure 4. (Continued)

ecology is even more striking when viewed in zonal collapse (Figure 4b). Strong regional convergences and divergences are again rendered obvious. Oligotrophic gyre perimeters display exceptionally steep gradients. An analogous, seasonally segregated presentation is organized in Figure 5 as derived from the Kettle data. Magnitudes and phasing are in general agreement. Linkage to the bloom phenomena does not appear to be as tight as in the simulations, but the provincial scale of resolution in the climatology renders contrasting difficult.

Since a strength of our approach lies in (ecochemical) eddy discrimination, we have in several earlier publications presented comparisons with individual ship track time series. Biogeochemical POP has proven particularly adept at representing the interaction of turbulent and ecological dynamics in the tropical Pacific (Chu et al., 2003). On an equatorial cruise extending westward from South America, Andreae and Raemdonck (Andreae and Raemdonck, 1983) were able to document manifold dimethyl sulfide concentration spikes rising upward from the usual baseline to several nanomolar. The peaks were on the order of $10-100 \mathrm{~km}$ in longitudinal extent. Our model has mimicked this behavior quite closely. It is traceable within the mechanism to a temporal offset of DMS production maxima relative to other geocycling components. Phase shifted sulfur chemistry is embedded in the ecology of tropical instability wave structures familiar from satellite chlorophyll data (Chavez et al., 1999). Nutrient-rich water masses reaching the surface are sculpted by shearing against the countercurrents. As stretching and 


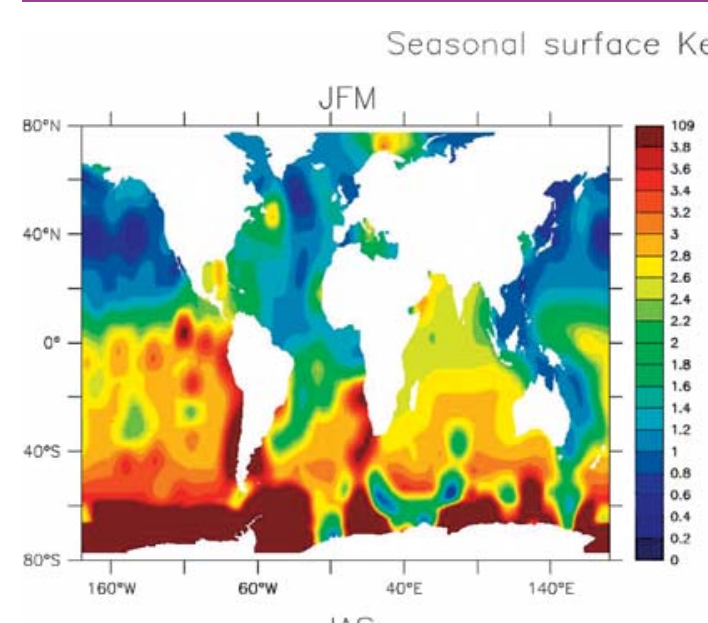

\section{Kettle DMS (nmol)}
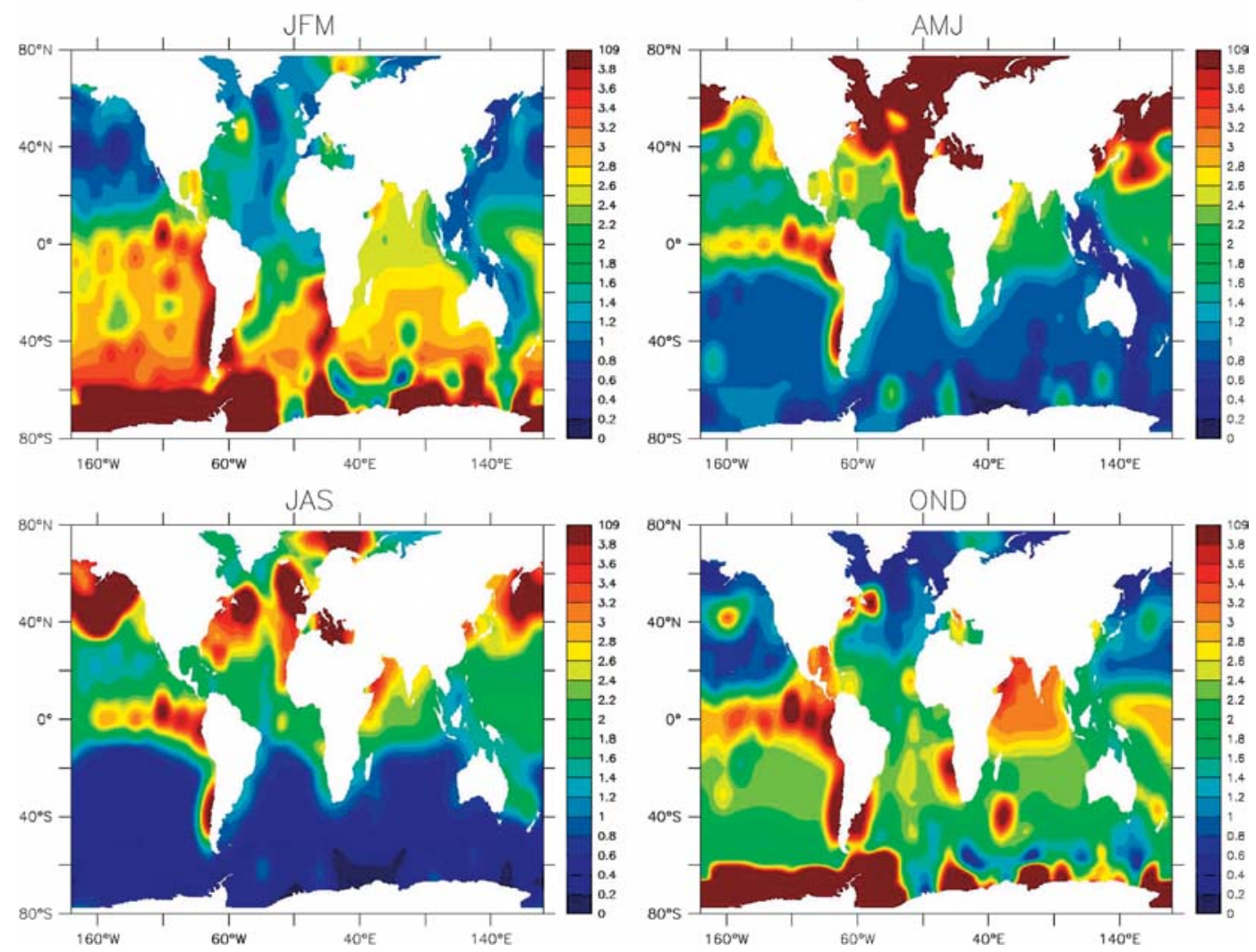

Figure 5. A seasonally averaged representation of the Kettle database. (Concentrations are expressed in $\mathrm{nM}$.)

filamentation set in, the bloom sequence initiates but sulfide release experiences a delay on the order of a few days (Gabric et al., 1993).

In the present analysis we will emphasize a newer, Atlantic ship track comparison. Working from the research vessel Polarstern in 1996, Belviso et al. (Belviso et al., 2000) obtained an Arctic to (near) Antarctic open-ocean dimethyl sulfide dataset. As in the Andreae and Raemdonck result, eddy structures are prominent and bands of high concentration can be observed (up to several nanomolar). The Polarstern cruise remained near $30^{\circ} \mathrm{W}$ longitude, with excursions of $\pm 5^{\circ}$ keeping the ship centered within the basins of the North and South Atlantic, respectively. In Figure 6 we present a bracketing meridional section taken through biogeochemical POP results during the same season. Modeled variability is similar to that in the measurements. Interannual biogeochemical differences are in general less pronounced in the Atlantic than in the much broader Pacific basin, but they exist nonetheless. The Belviso experiment was conducted several years prior to the simulation period of 1999. Frontal positions are then not expected to correspond precisely in latitude. Moreover, mesoscale eddies are necessarily chaotic so that energy distributions and biogeochemistry patterns should be reproducible statisti- 


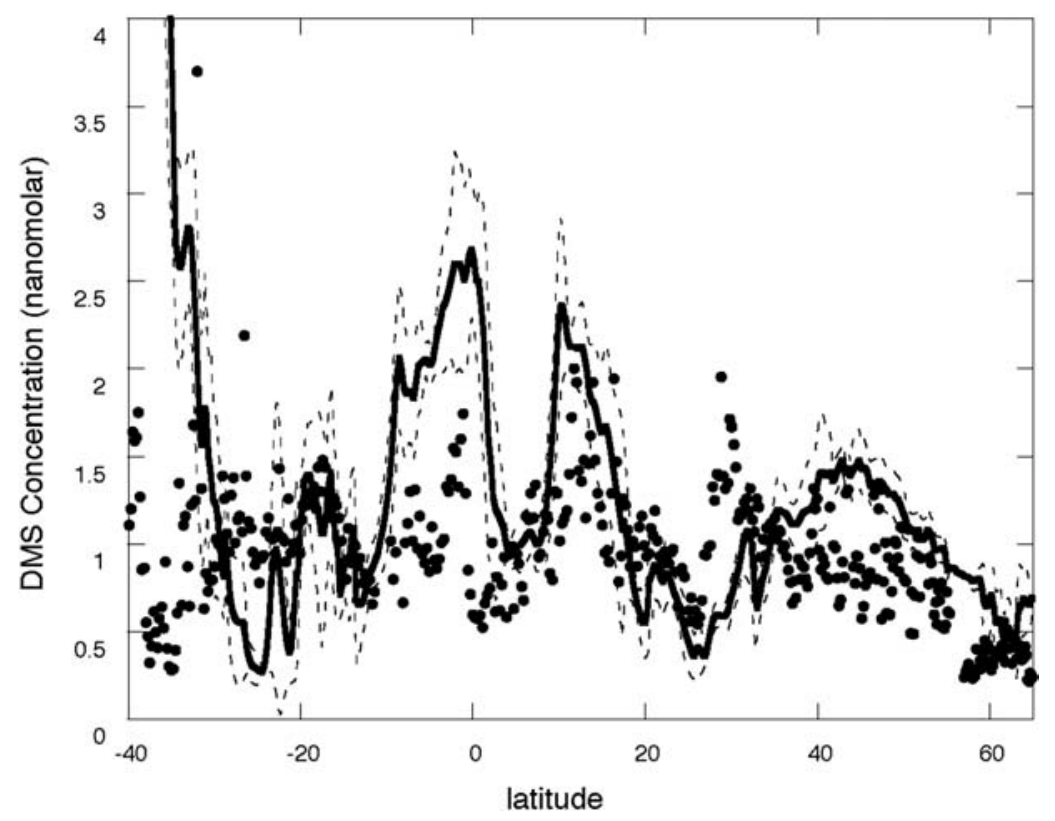

Figure 6. Dark solid curve gives a zonal average from $25^{\circ}$ to $35^{\circ} \mathrm{W}$ of the simulated Atlantic DMS distribution. Std dev is indicated by the surrounding dashes. The date of the calculations is $28 \mathrm{Oct}$, seasonally central to the recent oceanographic cruise of R/V Polarstern (Belviso et al., 2000). The ship-based DMS measurements are shown as solid circles.

cally but not exactly. The reader will also note that overprediction of the net equatorial divergence upwelling remains a problem.

Wind speed (and white cap)-dependent vertical gas transfer has been coupled to biogeochemical POP online following Erickson et al. (Erickson et al., 1990) and Erickson (Erickson, 1993). ECMWF data thus dictate with internal consistency both the DMS piston velocities and model mixed-layer transport. Specific interactions of the white cap parameterization with global sulfur cycling are described in the Kettle and Andreae (Kettle and Andreae, 2000) analysis. Global flux distributions derived from POP are compiled as annual averages in Figure 7. Seasonality was also computed and follows closely that of the concentrations themselves (see Figure 4) but with some modulation due to latitudinal dependence of the atmospheric data. Major marine frontal zones including western boundary current extensions, equatorial divergences/countercurrents, and circumpolars in the Southern Ocean are even more in evidence than for the simple concentration fields. Bacterial consumption is universally constrained in our relaxed Gabric mechanism to be more rapid than mixing toward the sea surface (Table 2). As the true province dependence of microbial counts is more accurately reflected, loss to the troposphere may provide a critical cap on local mixed-layer DMS levels in some locations.

We have postprocessed global-scale integrations of the fluxes in Figure 7 and 


\section{$7 a-$ Annual DMS air-sea flux $\left(\mathrm{mmol} / \mathrm{m}^{2} / \mathrm{day}\right)$}
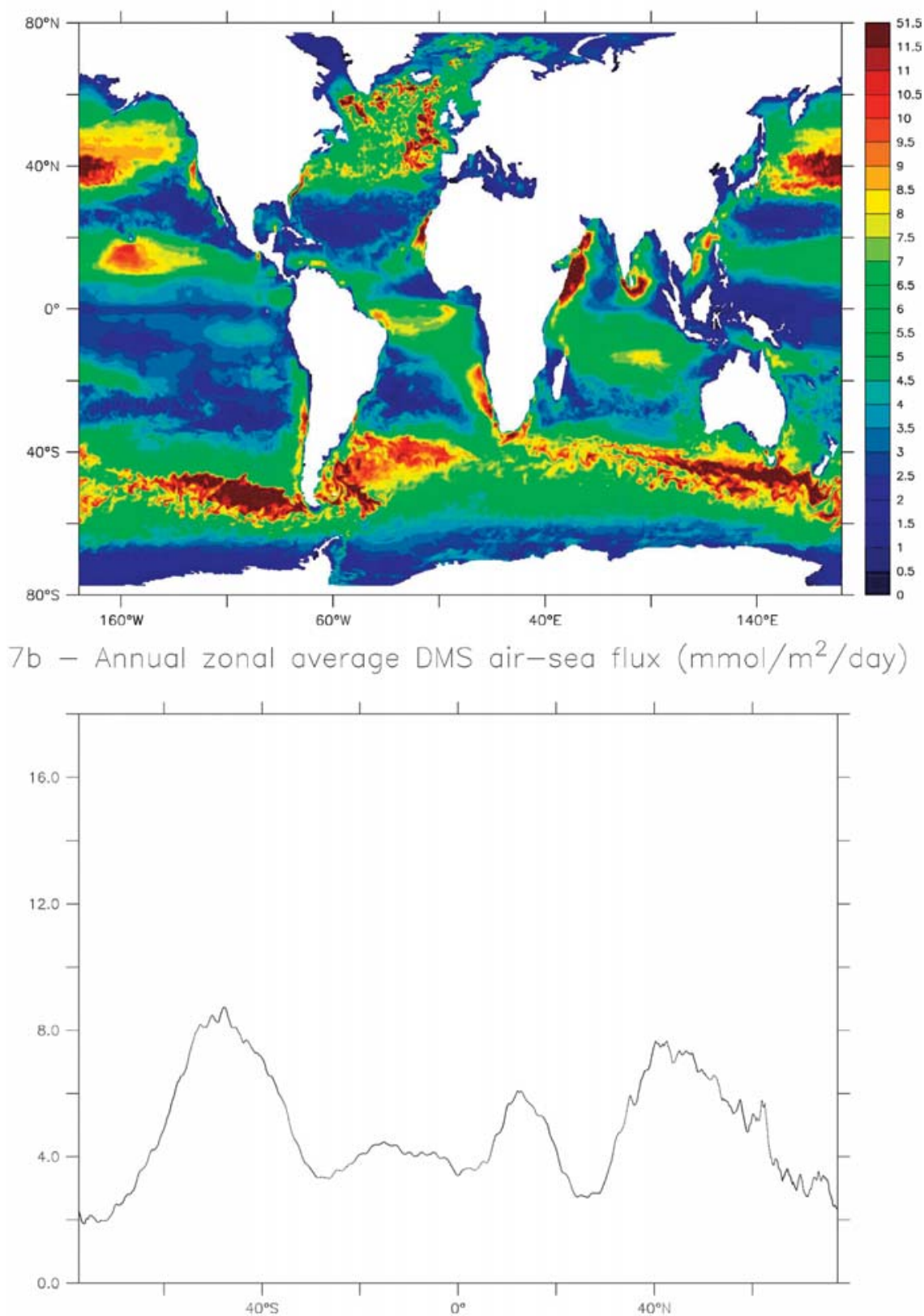

Figure 7. Annual average air-sea flux of DMS in the biogeochemical POP for (a) global and (b) zonal integration. (Units: $\mu \mathrm{mol} \mathrm{day}{ }^{-1} \mathrm{~m}^{-2}$.)

seasonal counterparts. A value of just over $20 \mathrm{Tg} \mathrm{S} \mathrm{yr}^{-1}$ is obtained. By way of comparison, Kettle and Andreae (Kettle and Andreae, 2000) compute 15-35 Tg $\mathrm{yr}^{-1}$ applying a variety of wind- and white-cap-linked transfer algorithms to the biogeographically smoothed climatology. Current versions of biogeochemical POP 
may provide fluxes that fall somewhat below the center of the community range. A portion of this small discrepancy is assignable to the planetary level offset toward low concentrations (Figures $1 \mathrm{~b}$ and 3 ). Since overall exudation rates are poorly constrained, the problem can be corrected in future runs.

\section{Discussion}

The global, eddy resolved dimethyl sulfide simulations we have so far conducted are successful in many aspects, but crucial deficiencies remain to be addressed. In this section we will emphasize first some continuing challenges in the parameterization of 1) microbial trace gas uptake and 2) exudation species dependence. We recommend that microscale studies be conducted both on the computer and in the laboratory, relevant to material processing by individual cells. It is argued that over large portions of the stratified central ocean, bacterial removal frequencies must fall substantially. If this were reflected in overall sulfide reaction rates and in our models, some of the agreement that we have displayed relative to climatology might be lost. Prospects are then to regain through a closer inspection of taxonomy for intracellular S cycling. The end of the discussion is devoted to broader scientific issues associated with our DMS work, and by extension the logic applies to global biogeochemistry computations in general. We point out that finely resolved, full geocycling models will play a central role in the interpretation of concentration patterns observed for other trace gases.

Bacterial uptake constants in our model are for the moment delimited by uncertainties in localized exercises of the Gabric group (Gabric et al., 1993; Gabric et al., 1995). Clearly, this constitutes something of a default position for sulfur process mechanisms. During preliminary parameter studies conducted in coarse and baseline biogeochemical POP versions (Chu and Elliott, 2001; Chu et al., 2003), microbial removal was fixed globally at the round central value of 1 day (Gabric et al., 1993). It was later determined that such averaging contributes significantly to the suppression of gyre concentrations. Recall that a key feature of the planetary-scale DMS climatology is flatness or evenness (Kettle et al., 1999; Kettle and Andreae, 2000). Reduction of diatomaceous precursor (DMSP) content and sulfur injection rates provided only a partial approach to updated Kettle patterns. The 1-day time constant for consumption by bacteria was thus relaxed and permitted to rise upward, reaching the Gabric maximum where chlorophyll content is lowest (Longhurst, 1998). Convergence with the DMS measurement database is attained, but it may to some degree be fortuitous. The model removal values span less than a factor of 10. Bacterial cell densities, on the other hand, drop by orders of magnitude in the oligotrophic central ocean (Parsons and Takahashi, 1973; Longhurst, 1998). Under the laws of either diffusion control or enzyme kinetics, first-order dependence of the net reaction rate on cell density should be in force over broad concentration ranges (Jumars, 1993; Sarmiento et al., 1993).

It is thus possible that for scales approaching those of a biogeographical province (Longhurst, 1998) and within the central open ocean, bacterial dimethyl sulfide uptake times should rise significantly. Distributions may then be moderated on the removal side mainly by photolysis and transport to the surface. We have 
estimated that concentration overprediction would result in biogeochemical POP, in the vicinity of $20^{\circ}-30^{\circ}$ latitude (either hemisphere). In some compilations of cell internal propionate content, coccolithophorids and related plant classes stand out among the nondiatoms (cf. Keller et al., 1989; Gabric et al., 1993). Smaller photosynthesizers such as synechococcus and the prochlorophytes are actually comparable to the bacillariophyceae in terms of their S chemistry. A thorough examination of the phytoplanktonic taxonomy of reduced sulfur cycling may well reveal factors compensating for any loss of bacterial concentration control. We hope to explore this concept in next-generation runs of both coarse- and fine-mode POP versions. In view of the planetary climate significance of dimethyl sulfide, microphysical modeling and laboratory work may be called for as well.

A program of study for the elucidation of these issues might run as follows. Analytical and numerical simulations would be configured regarding interactions between DMS molecules and bacteria over the range of a few individual cells suspended in bulk seawater. Mechanisms for contact through codiffusion, for passage of foodstuff across the external membrane, and finally for processing into protein synthesis and energy channels could all be represented consistent with the extant biophysics (Parsons and Takahasi, 1973; Andreae, 1986; Jumars, 1993). Results would be condensed into formulas for insertion sequentially into onedimensional, coarse global, and finally fine-mode biogeochemistry/transport frameworks. Concurrently, plant taxonomy would be more closely investigated for the subset sulfur chemistry. Class dependence of the intracellular DMSP content and residence period must be established to the extent possible based on the available literature, and then substantiated and refined through continued laboratory work. Under such a regimen it may be possible to demonstrate that microfluid dynamics or heterogeneous chemical considerations constrain the (kinetic) molecularity of DMS consumption rates, while release is restricted for nonprymnesiophytic photosynthesizers that populate the stratified sea surface. We intend to reflect at least some portion of this line of reasoning within full biogeochemical POP during near-term runs.

Our global dimethyl sulfide simulations are among the most detailed performed to date, and this is true at several levels. We begin from fine-resolution ocean physics modeling, which is nearly resolving of the major horizontal eddy systems (Maltrud et al., 1998). Since $1 / 10^{\circ}-1 / 16^{\circ}$ circulation calculations have been performed by members of our group, full discrimination of mesoscale turbulence is in the offing. To the fine-mode physics we add geocycling for the half dozen elements linked to major air-sea transfer drivers of global change (Houghton et al., 1996). The biogeochemistry routine is in itself comparable in complexity to others being employed to represent marine ecology at basin scales (Doney, 1999). We then center on one agent of communication between the marine and atmospheric chemical systems, the species DMS (Charlson et al., 1987). It is found that features of the observed distribution are clarified at all scales attainable (Kettle et al., 1999). The same approach could already be applied (Table 1) to comprehension of carbon dioxide partial pressure fields, for which climatologies are available along with many individual measurements. We anticipate that for non-DMS trace gases and in particular for methyl bromide (Chu and Elliott, 2001), data will soon be sufficiently 
dense to permit the construction of realistic large-scale summary sets. We plan to refine our computations for other geochemically crucial volatiles, in parallel with continued sulfur cycle work. The payoff in all cases will be increased confidence in the biophysical and chemical mechanisms applied by the community to interpret concentration patterns.

\section{Summary}

Surface ocean sulfur cycling exerts a disproportionate influence on global climate, through effects of the phytoplanktonic exudate dimethyl sulfide on radiation balance following its transition into the atmosphere (Andreae, 1986; Houghton et al., 1996; Kettle et al., 1999). The molecule is generated along protein synthesis, osmoregulatory or cryoprotection metabolic pathways in most marine plants. It is then released as a volatile by-product and undergoes trace gas transfer across the air-sea interface (Erickson et al., 1990). Within the troposphere, DMS oxidizes to aerosol sulfate, tuning cloud condensation nucleus fields and the remote cloud albedo in the process (Charlson et al., 1987). Time constants in the mixed-layer sulfur biogeochemical system are sufficiently short that horizontal turbulence and dimethyl sulfide distributions are intimately coupled (Andreae and Raemdonck, 1983; Gabric et al., 1993; Belviso et al., 2000; Chu et al., 2003). We report here on a set of simulations for this interaction that are both planetary and resolving of the major mesoscale oceanic eddies.

A finely gridded (global $1 / 5^{\circ}$ ) oceanic general circulation model (OGCM) has been developed that is equipped with multiple elemental geocycles and ecodynamical attenuation thereof (Maltrud et al., 1998; Chu et al., 2003). Along with carbon, nitrogen, iron, silicon, and chlorophyll, simulated marine plants contain DMS and the metabolic precursor dimethyl sulfoniopropionate (DMSP; Chu and Elliott, 2001; Chu et al., 2003). Within this DMS-augmented global biogeochemistry code, we perform calculations of the global distributions for sulfur. Boundary conditions are set at the level of the main thermocline such that biases with regard to convective sources/sinks may result for nutrients as well as the trace gas. The problems are likely restricted to the winter season and biogeographical zones of deep turnover (Longhurst, 1998). Detailed geocycling spinup is conducted over the half decade from 1995 to 2000, while results are presented for the typical year 1999.

Validation of the resulting DMS surface concentration distributions has relied largely upon the climatology constructed by Kettle and Andreae (Kettle and Andreae, 2000). We note that it is quite empirical; dynamics of the interactions of eddy physics with ecology are manifested only indirectly. We also point out that it is coarsely configured, in fact at the scale of the biogeographical province (Longhurst, 1998). Intercomparison with biogeochemical POP is in any case encouraging. Maxima and minima corresponding to those of plant density appear in both representations, with imprecise tracking indicating spatial and temporal lags. The gyre centers are uniformly low in free reduced sulfur forms. Global seasonality reflects in the main the well-understood dynamics of midlatitude phytoplankton blooms (Parsons and Takahashi, 1973; Mann and Lazier, 1996). Along the equator, POP concentration patterns are heavily influenced by tropical 
instability waves and their interannuual variability (Chavez et al., 1999). Naturally, we remark that the simulations are much more finely resolved than information from the Kettle analysis.

Discrepancies relative to Kettle are documented in several geophysically crucial areas. Coastal and shelf zone concentrations are poorly captured in some cases. We attribute this preliminarily to the omission of sediment and lithospheric geochemistry. Shelf geocycling must clearly be incorporated into future biogeochemical POP versions. A dataset peak surrounding Antarctica does not appear in the model. We hypothesize that this may be related to specialized polar biology, or even to the peculiarities of ice front ecosystems. In addition to the global climatology work, model sections are discussed in relation to several basinscale ship tracks (Andreae and Raemdonck, 1983; Belviso et al., 2000). Emphasis here is placed upon the North and South Atlantic because successful Pacific intercomparisons have been presented in the past (Chu et al., 2003). We note that while eddy variability manifested in the data and model is in resemblance, interannual effects translate to a lack of correspondence. Even in the tropical Atlantic, year-to-year variation is a significant factor in determining plant and DMS distributions. Dates for the simulation- and ship-based experiments could not be matched. Incidentally, we associate peaks at the equatorial upwelling with overtransportation by the OGCM of nutrient material from the thermocline. Related problems exist at the Kuroshio Extension. We postulate that as biogeochemistry is incorporated into even more finely resolved POP versions, vertical mixing properties will attain greater fidelity in such areas.

Flux maps are computed based on the model DMS distributions. Maxima and minima in air-sea transfer tend to mimic those of the molecule itself but are modulated by the effect of global wind systems upon piston velocity (Erickson et al., 1990; Erickson, 1993). The fluxes are integrated over the planetary ocean and compared with conclusions drawn from coarser and more empirical approaches (Kettle and Andreae, 2000). Biogeochemical POP results fall on the low side of recent transfer estimates. This derives in part from an overall concentration undershoot and can be rectified in next-generation runs through a slight adjustment to exudation rates. A concluding discussion section elaborates upon several potential lines of self-criticism. We point out that the parameterization of DMS bacterial uptake is currently limited by uncertainty estimates in some original mechanism papers (Gabric et al., 1993; Chu and Elliott, 2001; Chu et al., 2003). Allowance should be made for the microbiophysics of interaction between DMS molecules and individual cells (Mann and Lazier, 1996; Longhurst, 1998). When this occurs the intracellular DMSP content of gyre species may be an issue (Keller et al., 1989).

Acknowledgments. We thank the U.S. Department of Energy's Office of Science (BER) Scientific Discovery through Advanced Computing (SciDAC) program, GreenSea Venture, Inc., and the Los Alamos Laboratory-Directed Research \& Development (LDRD) program for support of this work. 


\section{References}

Andreae, M.O., 1986: The ocean as a source of atmospheric sulfur compounds. The Role of Air-Sea Exchange in Geochemical Cycling, P. Buat Menard, Ed., D. Reidel, 331-362. , and H. Raemdonck, 1983: Dimethyl sulfide in the surface ocean and the marine atmosphere: A global view. Science, 221, 744-747.

Aumont, O., S. Belviso, and P. Monfray, 2002: Dimethylsulfoniopropionate (DMSP) and dimethylsulfide (DMS) sea surface distributions simulated from a global three-dimensional ocean carbon cycle model. J. Geophys. Res., 107, 3029, doi:10.1029/1999JC000111.

Bacastow, R., and E. Maier Reimer, 1990: Ocean circulation model of the carbon cycle. Climate Dyn., 4, 95-125.

Barnier, B., L. Siefridt, and P. Marchesiello, 1995: Thermal forcing for a global ocean circulation model using a 3 year climatology of ECMWF analyses. J. Mar. Syst., 6, 363380.

Belviso, S., R. Morrow, and R. Mihalopoulos, 2000: An Atlantic meridional transect of surface water dimethyl sulfide concentrations with 10 to 15 kilometer horizontal resolution and close examination of ocean circulation. J. Geophys. Res., 105, 14 423-14 431.

Broecker, W.S., and T.H. Peng, 1982: Tracers in the Sea. Eldigio Press, 690 pp.

, D.W. Spencer, and H. Craig, 1982: GEOSECS Pacific Expedition, Hydrographic Data.Vol. 3, U.S. National Science Foundation, 136 pp.

Chai, F.C., R.C. Dugdale, T.H. Peng, F.P. Wilkerson, and R. Barber, 2002: One dimensional ecosystem model of the equatorial Pacific upwelling system. I: Model development and silicon and nitrogen cycles. Deep-Sea Res., 49B, 2713-2745.

Charlson, R.J., J.E. Lovelock, M.O. Andreae, and S.G. Warren, 1987: Oceanic phytoplankton, atmospheric sulfur, cloud albedo and climate. Nature, 326, 655-661.

Chavez, F.C., P.G. Strutton, G.E. Friederich, R.A. Feely, G.C. Feldman, D.G. Foley, and M.J. McPhaden, 1999: Biological and chemical response of the equatorial Pacific Ocean to the 1997-1998 El Niño. Science, 286, 2126-2131.

Chu, S., and S. Elliott, 2001: Latitude versus depth simulation of ecodynamics and dissolved gas chemistry relationships in the central North Pacific. J. Atmos. Chem., 40, 305-333.

- - $\longrightarrow$, and M. Maltrud, 2003: Global eddy permitting simulations of surface ocean N, Fe, S cycling. Chemosphere: Global Change Sci., 50, 223-235.

Doney, S.C., 1999: Major challenges confronting marine biogeochemical modelers. Global Biogeochem. Cycles, 13, 705-714.

Dugdale, R., and F. Wilkerson, 1998: Silicate regulation of new production in the equatorial Pacific upwelling. Nature, 391, 270-273.

Dukowicz, J.K., R.D. Smith, and R.C. Malone, 1993: A reformulation and implementation of the Bryan-Cox-Semtner ocean model on the connection machine. J. Atmos. Oceanic Technol., 10, 195-208.

Erickson, D.J., III, 1993: A stability dependent theory for air-sea gas exchange. J. Geophys. Res., 98, 8471-8488.

- S.J. Ghan, and J.E. Penner, 1990: Global ocean to atmosphere dimethyl sulfide flux. $J$. Geophys. Res., 95, 7543-7552.

Fasham, M.J.R., H.W. Ducklow, and S.M. McKelvie, 1990: A nitrogen based model of plankton dynamics in the oceanic mixed layer. J. Mar. Res., 35, 357-394.

— J.L. Sarmiento, R.D. Slater, H.W. Ducklow, and R. Williams, 1993: Ecosystem behavior at Bermuda station $\mathrm{S}$ and ocean weather station India: A general circulation model and observational analysis. Global Biogeochem. Cycles, 7, 379-416. 
Fung, I.Y., S.K. Meyu, I. Tegen, S.C. Doney, J.G. John, and J.K.B. Bishop, 2000: Iron supply and demand in the upper ocean. Global Biogeochem. Cycles, 14, 281-295.

Gabric, A., N. Murray, L. Stone, and M. Kohl, 1993: Modeling the production of dimethylsulfide during a phytoplankton bloom. J. Geophys. Res., 98, 22 805-22 816.

— G.P. Ayers, and G.C. Sander, 1995: Independent marine and atmospheric model estimates of the sea-air flux of dimethyl sulfide in the Southern Ocean. Geophys. Res. Lett., 22, 3521-3524.

Garfield, N., M.E. Maltrud, C.A. Collins, T.A. Rago, and R.G. Paquette, 2001: Lagrangian flow in the California undercurrent, an observation and model comparison. J. Mar. Syst., 29, 201-220.

Gurney, R.J., J.L. Foster, and C.L. Parkinson, 1993: Atlas of Satellite Observations Related to Global Change. Cambridge University Press, $470 \mathrm{pp}$.

Houghton, J.T., L.G. Meira Filho, B.A. Callander, N. Harris, A. Kattenberg, and K. Maskell, Eds., 1996: Climate Change 1995: The Science of Climate Change. Cambridge University Press, $572 \mathrm{pp}$.

Jiang, M.S., F. Chai, R.C. Dugdale, F.P. Wilkerson, T.H. Peng, and R.T. Barber, 2003: A nitrate and silicate budget in the equatorial Pacific Ocean: Coupled physical-biological model study. Deep-Sea Res. II, 50, 2971-2996.

Jumars, P.A., 1993: Concepts in Biological Oceanography: An Interdisciplinary Primer. Oxford University Press, $348 \mathrm{pp}$.

Keller, M.D., W.K. Bellows, and R.R.L. Guillard, 1989: Dimethyl sulfide production by marine phytoplankton. Biogenic Sulfur in the Environment, ACS Symposium Series 393, E. Saltzman and W.J. Cooper, Eds., American Chemical Society, 167-181.

Kettle, A.J., and M.O. Andreae, 2000: Flux of dimethyl sulfide from the oceans: A comparison of updated data sets and flux models. J. Geophys. Res., 105, 26 793-26 808.

— and a procedure to predict sea surface DMS as a function of latitude, longitude and month. Global Biogeochem. Cycles, 13, 399-444.

Kiene, R.P., and T.S. Bates, 1990: Biological removal of dimethyl sulphide from sea water. Nature, 345, 702-705.

Lefevre, N., and A.J. Watson, 1999: Modeling the geochemical cycle of iron in the oceans and its impact on atmospheric $\mathrm{CO}_{2}$ concentrations. Global Biogeochem. Cycles, 13, 727-736.

Levitus, S., 1982: Climatological Atlas of the World Ocean. NOAA Prof. Paper 13, 173 pp. and 17 microfiche. , M. Conkright, J.L. Reid, R.G. Najjar, and A. Mantyla, 1993: Distribution of nitrate phosphate and silicate in the world oceans. Progress in Oceanography, Vol. 31, Pergamon, 245-273.

Li, Y.H., T.H. Peng, W.S. Broecker, and H.G. Ostlund, 1984: The average vertical mixing coefficient for the oceanic thermocline. Tellus, 36B, 212-217.

Longhurst, A., 1998: Ecological Geography of the Sea. Academic Press, 398 pp.

Maier Reimer, E., 1993: Geochemical cycles in an ocean general circulation model: Preindustrial tracer distributions. Global Biogeochem. Cycles, 7, 645-677.

Maltrud, M.E., R.D. Smith, A.J. Semtner, and R.C. Malone, 1998: Global eddy resolved ocean simulations driven by 1985-1995 atmospheric winds. J. Geophys. Res., 103, 30 825-30 853.

Mann, K.H., and J.R.N. Lazier, 1996: Dynamics of Marine Ecosystems: Biological-Physical Interactions in the Oceans. 2d ed. Blackwell Science, 394 pp.

McGillicuddy, D.J., L.A. Anderson, S.C. Doney, and M.E. Maltrud, 2003: Eddy driven 
sources and sinks of nutrients in the upper ocean: Results from a 0.1 degree resolution model of the North Atlantic. Global Biogeochem. Cycles, 17, 1035-1047.

Moore, J.K., S.C. Doney, J. Kleypas, D.M. Glover, and I.Y. Fung, 2002: An intermediate complexity ecosystem model for the global domain. Deep-Sea Res., 49B, 403-462.

Morel, F.M.M., and N.M. Price, 2003: The biogeochemical cycles of trace metals in the oceans. Science, 300, 944-947.

Parsons, T., and M. Takahashi, 1973: Biological Oceanographic Processes. Pergamon, 186 pp.

Ryabchenko, V.A., M.J.R. Fasham, B.A. Kagan, and E.E. Popova, 1997: What causes short term oscillations in ecosystem models of the ocean mixed layer? J. Mar. Syst., 13, 33-50.

Sarmiento, J.L., and J.C. Orr, 1991: Three dimensional simulations of the impact of Southern Ocean nutrient depletion on atmospheric $\mathrm{CO}_{2}$ and ocean chemistry. Limnol. Oceanogr., 36, 1928-1950.

, R.D. Slater, M.J.R. Fasham, H.W. Ducklow, J.R. Toggweiler, and G.T. Evans, 1993: A seasonal three dimensional ecosystem model of nitrogen cycling in the North Atlantic euphotic zone. Global Biogeochem. Cycles, 7, 417-450.

Smith, R.D., M.E. Maltrud, F.O. Bryan, and M.W. Hecht, 2000: Numerical simulation of the North Atlantic Ocean at $1 / 10^{\circ}$. J. Phys. Oceanogr., 30, 1532-1561.

Takahashi, T., W.S. Broecker, and S. Langer, 1985: Redfield ratio estimates based on chemical data from isopycnal surfaces. J. Geophys. Res., 90, 5907-5924.

van den Berg, A.J., S.M. Turner, F.C. van Duyl, and P. Ruardij, 1996: Model structure and analysis of dimethylsuphide production in the southern North Sea. Ecol. Prog. Ser., 145, 233-244.

Watson, A.J., and P.S. Liss, 1998: Marine biological controls on climate via the carbon and sulphur geochemical cycles. Philos. Trans. Roy. Soc. London, B353, 41-51.

Earth Interactions is published jointly by the American Meteorological Society, the American Geophysical Union, and the Association of American Geographers. Permission to use figures, tables, and brief excerpts from this journal in scientific and educational works it hereby granted provided that the source is acknowledged. Any use of material in this journal that is determined to be "fair use" under Section 107 or that satisfies the conditions specified in Section 108 of the U.S. Copyright Law (17 USC, as revised by P.IL. 94553) does not require the publishers' permission. For permission for any other form of copying, contact one of the copublishing societies. 